\title{
EVALUASI KESESUAIAN LAHAN KUALITATIF DAN KUANTITATIF PERTANAMAN PADI GOGO (Oryza sativa L.) DI LABORATORIUM LAPANG TERPADU FAKULTAS PERTANIAN UNIVERSITAS LAMPUNG
}

\author{
Ade Suryani, Irwan Sukri Banuwa, Kuswanta F. Hidayat \& Tamaluddin Syam \\ Jurusan Agroteknologi Fakultas Pertanian Universitas Lampung, \\ J1. Prof Soemantri Brodjonegoro No. 1 Bandar Lampung 35143 \\ Email: ades2772@gmail.com
}

\begin{abstract}
ABSTRAK
Produksi padi nasional selama ini belum dapat memenuhi kebutuhan dalam negeri. Faktor penyebabnya adalah menurunnya produktivitas lahan pertanian, alih fungsi lahan, serta ketersediaan lahan kering yang belum dimanfaatkan secara optimal hingga \pm 35 juta ha yang tersebar di Sumatera, Kalimantan, Sulawesi, dan Irian Jaya. Diperlukan pengetahuan mengenai evaluasi lahan secara kualitatif dan kuantitatif. Penelitian dilaksanakan pada 5 unit lahan pertanaman padi gogo di Laboratorium Lapang Terpadu Fakultas Pertanian Universitas Lampung. Penanaman dilakukan di setiap unit lahan berukuran $2 \times 3 \mathrm{~m}$ dengan 2 kali ulangan. Analisis tanah dilakukan di Laboratorium Ilmu Tanah Fakultas Pertanian Universitas Lampung. Tujuan penelitian ini adalah untuk mengevaluasi kesesuaian lahan kualitatif pertanaman padi gogo di Laboratorium Lapang Terpadu Fakultas Pertanian Universitas Lampung, berdasarkan kriteria Djaenudin dkk. (2003) dan untuk mengevaluasi kesesuaian lahan kuantitatif dengan menganalisis kelayakan finansial tanaman padi gogo di Laboratorium Lapang Terpadu Fakultas Pertanian Universitas Lampung. Hasil penelitian menunjukkan bahwa pada Unit lahan 1, 2, dan 3 sesuai marginal dengan faktor pembatas ketersediaan air, pada Unit lahan 4 sesuai marginal dengan faktor pembatas ketersediaan air dan lereng yang dapat menyebabkan bahaya erosi, dan Unit lahan 5 tidak sesuai dengan faktor pembatas lereng sehingga dapat menyebabkan bahaya erosi. Unit lahan 2, 3, 4, dan 5 secara finansial menguntungkan, hal ini dibuktikan dari hasil perhitungan yang menunjukkan bahwa nilai $\mathrm{R} / \mathrm{C}>1$.
\end{abstract}

Kata kunci: kelayakan finansial, kesesuaian lahan, kualitatif, kuantitatif, padi gogo

\section{PENDAHULUAN}

Padi (Oryza sativa L.) merupakan makanan pokok sebagian besar masyarakat Indonesia yang harus dipenuhi kebutuhannya. Pada saat ini, masalah yang dihadapi sektor pertanian adalah menurunnya produktivitas lahan. Sejalan dengan pesatnya pembangunan di berbagai bidang setiap tahun sekitar 50.000 ha lahan produktif beralih fungsi ke sektor nonpertanian, seperti untuk pemukiman, industri, dan transportasi/jalan (Prasetyo, 2007).

Selama ini, produksi padi nasional masih mengandalkan sawah irigasi yang tentunya akan menghadapi banyak kendala nantinya. Hal tersebut disebabkan oleh lahan sawah irigasi subur yang dialihfungsikan menjadi lahan non-pertanian, biaya pencetakan sawah yang tinggi, serta ketersediaan air yang semakin berkurang. Di sisi lain, lahan kering tersedia cukup luas namun pemanfaatannya belum optimal. Padahal padi dapat dibudidayakan di lahan kering yang dikenal sebagai padi gogo (Pujiharti dkk., 2008). Oleh karena itu, dilakukan penelitian yang bertujuan untuk mengevaluasi kesesuaian lahan kualitatif tanaman padi gogo (Oryza sativa L.) di Laboratorium Lapang Terpadu Fakultas Pertanian Universitas Lampung berdasarkan kriteria kelas kesesuaian Djaenudin dkk. (2003) dan mengevaluasi kesesuaian lahan kuantitatif dengan menganalisis kelayakan finansial tanaman padi gogo (Oryza sativa L.) di Laboratorium Lapang Terpadu Fakultas Pertanian Universitas Lampung.

\section{BAHAN DAN METODE}

Penelitian ini dilaksanakan di Laboratorium Lapang Terpadu Fakultas Pertanian Universitas Lampung mulai bulan Mei-September 2015 di 5 unit lahan pertanaman padi gogo dan analisis tanah dilakukan di Laboratorium Ilmu Tanah Jurusan Agroteknologi Fakultas Pertanian Universitas Lampung.

Penelitian ini dilakukan dengan menggunakan metode survei dengan pendekatan evaluasi lahan secara paralel, yaitu melakukan evaluasi kualitatif dan kuantitatif secara bersamaan berdasarkan kriteria fisik Djaenuddin 
dkk. (2003) dan analisis kelayakan finansial tanaman padi gogo (L.) dengan menilai Revenue Cost Rasio (R/ C Rasio). Pelaksanaan survei dilakukan dengan beberapa tahap, yaitu tahap persiapan, pengumpulan data, dan analisis data.

Data yang dikumpulkan meliputi data fisik primer dan data fisik sekunder. Data fisik primer yang dikumpulkan meliputi seluruh indikator kesesuaian Djaenuddin. Pengumpulan data fisik sekunder meliputi data curah hujan selama 5 tahun terakhir. Data sosial ekonomi yang dikumpulkan meliputi data primer dan data sekunder. Data primer meliputi biaya tetap, yaitu biaya sewa lahan, sedangkan biaya variabel meliputi biaya produksi (benih dan pupuk), peralatan, tenaga kerja (pengolahan tanah, penanaman, penyiraman, pemupukan, pengendalian hama penyakit, panen, dan lain-lain), dan pendapatan yang diperoleh. Data sosial ekonomi yang dikumpulkan sebagai data sekunder, yaitu data luas panen dan produksi tanaman padi gogo di Provinsi Lampung.

Metode analisis tanah di laboratorium adalah tanah dikering udarakan selama 7-10 hari. Tanah yang telah dikeringkan tersebut diayak dengan ayakan $2 \mathrm{~mm}$. Kemudian tanah yang lolos saringan ayakan $2 \mathrm{~mm}$ tersebut dianalisis di Laboratorium Ilmu Tanah Fakultas Pertanian Universitas Lampung.

Analisis kesesuaian lahan kualitatif dilakukan dengan cara membandingkan kondisi fisik lingkungan dengan persyaratan tumbuh tanaman padi gogo (Oryza sativa L.) berdasarkan kriteria Djaenuddin dkk. (2003) dengan menilai kualitas dan karakteristik lahan di lapang.

Analisis kesesuaian lahan kuantitatif dilakukan dengan cara melakukan analisis finansial dengan menghitung $R / C$ Ratio.untuk mengetahui kelayakan usaha tanaman padi gogo (Oryza sativa L.). Menurut Soekartawi (1995), $R / C$ ratio adalah singkatan dari Revenue Cost Ratio, atau dikenal sebagai perbandingan (nisbah) antara penerimaan dan biaya. Secara teoritis dengan rasio $\mathrm{R} / \mathrm{C}=1$ artinya tidak untung dan tidak rugi, jika nilai $\mathrm{R} / \mathrm{C}>1$ usahatani yang dilakukan adalah layak sedangkan jika $\mathrm{R} / \mathrm{C}<1$ maka usahatani yang dilakukan tidak layak. Berikut merupakan cara menghitung Revenue Cost Ratio (R/C Ratio).

$$
\mathrm{R} / \mathrm{C}=\mathrm{P}_{\mathrm{Q}} \cdot \mathrm{Q} /(\mathrm{TFC}=\mathrm{TVC})
$$

$$
\begin{array}{ll}
\text { Keterangan: } & \\
\mathrm{R}=\text { Penerimaan } & \mathrm{P}_{\mathrm{Q}}=\text { Harga output } \\
\mathrm{C}=\text { Biaya } & \mathrm{Q}=\text { Output } \\
\text { TFC }=\text { Biaya tetap }(\text { fived cost }) \\
\text { TVC }=\text { Biaya Variabel }(\text { variable cost })
\end{array}
$$

\section{PENDAHULUAN}

Padi (Oryza sativa L.) merupakan makanan pokok sebagian besar masyarakat Indonesia yang harus dipenuhi kebutuhannya. Pada saat ini, masalah yang dihadapi sektor pertanian adalah menurunnya produktivitas lahan. Sejalan dengan pesatnya pembangunan di berbagai bidang setiap tahun sekitar 50.000 ha lahan produktif beralih fungsi ke sektor nonpertanian, seperti untuk pemukiman, industri, dan transportasi/jalan (Prasetyo, 2007).

Selama ini, produksi padi nasional masih mengandalkan sawah irigasi yang tentunya akan menghadapi banyak kendala nantinya. Hal tersebut disebabkan oleh lahan sawah irigasi subur yang dialihfungsikan menjadi lahan non-pertanian, biaya pencetakan sawah yang tinggi, serta ketersediaan air yang semakin berkurang. Di sisi lain, lahan kering tersedia cukup luas namun pemanfaatannya belum optimal. Padahal padi dapat dibudidayakan di lahan kering yang dikenal sebagai padi gogo (Pujiharti dkk., 2008). Oleh karena itu, dilakukan penelitian yang bertujuan untuk mengevaluasi kesesuaian lahan kualitatif tanaman padi gogo (Oryza sativa L.) di Laboratorium Lapang Terpadu Fakultas Pertanian Universitas Lampung berdasarkan kriteria kelas kesesuaian Djaenudin dkk. (2003) dan mengevaluasi kesesuaian lahan kuantitatif dengan menganalisis kelayakan finansial tanaman padi gogo (Oryza sativa L.) di Laboratorium Lapang Terpadu Fakultas Pertanian Universitas Lampung.

\section{BAHAN DAN METODE}

Penelitian ini dilaksanakan di Laboratorium Lapang Terpadu Fakultas Pertanian Universitas Lampung mulai bulan Mei-September 2015 di 5 unit lahan pertanaman padi gogo dan analisis tanah dilakukan di Laboratorium Ilmu Tanah Jurusan Agroteknologi Fakultas Pertanian Universitas Lampung.

Penelitian ini dilakukan dengan menggunakan metode survei dengan pendekatan evaluasi lahan secara paralel, yaitu melakukan evaluasi kualitatif dan kuantitatif secara bersamaan berdasarkan kriteria fisik Djaenuddin dkk. (2003) dan analisis kelayakan finansial tanaman padi gogo dengan menilai Revenue Cost Rasio (R/C Rasio). Pelaksanaan survei dilakukan dengan beberapa tahap, yaitu tahap persiapan, pengumpulan data, dan analisis data.

Data fisik primer yang dikumpulkan meliputi data fisik primer dan data fisik sekunder. Data yang dikumpulkan meliputi seluruh indikator kesesuaian 
Djaenuddin. Pengumpulan data fisik sekunder meliputi data curah hujan selama 5 tahun terakhir. Data sosial ekonomi yang dikumpulkan meliputi data primer dan data sekunder. Data primer meliputi biaya tetap, yaitu biaya sewa lahan, sedangkan biaya variabel meliputi biaya produksi (benih dan pupuk), peralatan, tenaga kerja (pengolahan tanah, penanaman, penyiraman, pemupukan, pengendalian hama penyakit, panen, dan lain-lain), dan pendapatan yang diperoleh. Data sosial ekonomi yang dikumpulkan sebagai data sekunder, yaitu data luas panen dan produksi tanaman padi gogo di Provinsi Lampung.

Metode analisis tanah di laboratorium dimulai dari tanah dikering-udarakan selama 7-10 hari. Tanah yang telah dikeringkan tersebut diayak dengan ayakan $2 \mathrm{~mm}$. Kemudian tanah yang lolos saringan ayakan $2 \mathrm{~mm}$ tersebut dianalisis di Laboratorium Ilmu Tanah Fakultas Pertanian Universitas Lampung.

Analisis kesesuaian lahan kualitatif dilakukan dengan cara membandingkan kondisi fisik lingkungan dengan persyaratan tumbuh tanaman padi gogo (Oryza sativa L.) berdasarkan kriteria Djaenuddin dkk. (2003) dengan menilai kualitas dan karakteristik lahan di lapang.

Analisis kesesuaian lahan kuantitatif dilakukan dengan cara melakukan analisis finansial dengan menghitung $R / C$ Ratio.untuk mengetahui kelayakan usaha tanaman padi gogo (Oryza sativa L.). Menurut Soekartawi (1995), $R / C$ ratio adalah singkatan dari Revenue Cost Ratio, atau dikenal sebagai perbandingan (nisbah) antara penerimaan dan biaya. Secara teoritis dengan rasio $\mathrm{R} / \mathrm{C}=1$ artinya tidak untung dan tidak rugi, jika nilai $\mathrm{R} / \mathrm{C}>1$ usahatani yang dilakukan adalah layak sedangkan jika $\mathrm{R} / \mathrm{C}<1$ maka usahatani yang dilakukan tidak layak. Berikut merupakan cara menghitung Revenue Cost Ratio (R/C Ratio).

$$
\mathrm{R} / \mathrm{C}=\mathrm{P}_{\mathrm{Q}} \cdot \mathrm{Q} /(\mathrm{TFC}=\mathrm{TVC})
$$

Keterangan :

$\mathrm{R}=$ Penerimaan

$\mathrm{C}$ = Biaya

$\mathrm{P}_{\mathrm{Q}}=$ Harga output

$\mathrm{Q}=$ Output

$\mathrm{TFC}=$ Biaya tetap (fived cost)

$\mathrm{TVC}=$ Biaya Variabel (variable cost)

\section{HASIL DAN PEMBAHASAN}

Penilaian kesesuaian lahan kualitatif berdasarkan kriteria biofisik untuk tanaman padi gogo didasarkan pada kualitas dan karakteristik lahan Laboratorium Lapang Terpadu Fakultas Pertanian Universitas
Lampung yang dibandingkan dengan syarat tumbuh tanaman padi gogo berdasarkan kriteria Djaenudin dkk. (2003). Berdasarkan hasil pengamatan dan pengukuran karakteristik lahan, maka kelas kesesuaian lahan untuk tanaman padi gogo di lokasi penelitian selengkapnya tertera pada Tabel 1 .

Berdasarkan hasil pengamatan dan karakteristik lahan pada Tabel 1, maka didapat kelas kesesuaian lahan untuk tanaman padi gogo di lokasi penelitian yang termasuk ke dalam kelas sesuai marginal dengan faktor pembatas ketersediaan air adalah pada unit lahan 1, 2, dan 3. Pada unit lahan 4 termasuk ke dalam kelas sesuai marginal dengan faktor pembatas ketersediaan air, kemiringan lereng, dan bahaya erosi, sedangkan pada unit lahan 5 termasuk ke dalam kelas tidak sesuai dengan faktor pembatas kemiringan lereng dan bahaya erosi.

Analisis Kuantitatif. Biaya tetap adalah biaya yang besar kecilnya tidak tergantung biaya produksi yang dihasilkan dan penggunaannya tidak habis dalam satu kali masa produksi. Biaya tetap terdiri dari sewa tanah dan peralatan. Biaya variabel merupakan biaya yang besar kecilnya mempengaruhi jumlah produksi. Biaya variabel terdiri dari benih, pupuk, dan tenaga kerja. Penerimaan pada analisis finansial penelitian ini bersumber dari hasil penjualan gabah kering panen (GKP) dengan harga Rp 5.500,00/kg.

Analisis finansial dilakukan dengan menghitung nilai $\mathrm{R} / \mathrm{C}$ ratio, yaitu perbandingan antara penerimaan dan pengeluaran. Nilai $\mathrm{R} / \mathrm{C}$ pada Unit lahan 1 sebesar 0,431 , nilai $\mathrm{R} / \mathrm{C}$ pada Unit lahan 2 sebesar 1,004 nilai $\mathrm{R} / \mathrm{C}$ pada Unit lahan 3 sebesar 1,141 , nilai $\mathrm{R} / \mathrm{C}$ pada Unit lahan 4 sebesar 1,184, dan nilai R/C pada Unit lahan 5 sebesar 1,483.

Berdasarkan hasil penelitian yang telah dilakukan, baik secara langsung di lapang maupun analisis di Laboratorium, setelah dicocokkan dengan kriteria Djaenudin dkk. (2003), pada setiap Unit lahan memiliki faktor pembatas yang berbeda-beda. Pada Unit lahan 1, 2, dan 3 memiliki faktor pembatas ketersediaan air (curah hujan) sebesar $<50 \mathrm{~mm}$ pada bulan pertama dan $<100 \mathrm{~mm}$ pada bulan kedua - keempat sehingga termasuk ke dalam kelas kesesuaian lahan (S3wa), Unit lahan 4 memiliki faktor pembatas ketersediaan air (curah hujan) sebesar $<50 \mathrm{~mm}$ pada bulan pertama dan $<100$ mm pada bulan kedua - keempat dan lereng $15-30 \%$ (S3wa.eh), dan Unit lahan 5 memiliki faktor pembatas lereng $30-45 \%$ dan bahaya erosi sangat berat (Neh).

Berdasarkan analisis karakteristik lahan, maka penilaian kelas kesesuaian lahan untuk tanaman padi gogo pada Unit lahan 1, 2, dan 3 termasuk dalam kelas sesuai marginal dengan faktor pembatas ketersediaan 
Tabel 1. Evaluasi Kesesuaian Lahan Aktual Tanaman Padi Gogo (Oryza sativa L.) pada semua unit lahan menurut Kriteria Djaenuddin dkk. (2003)

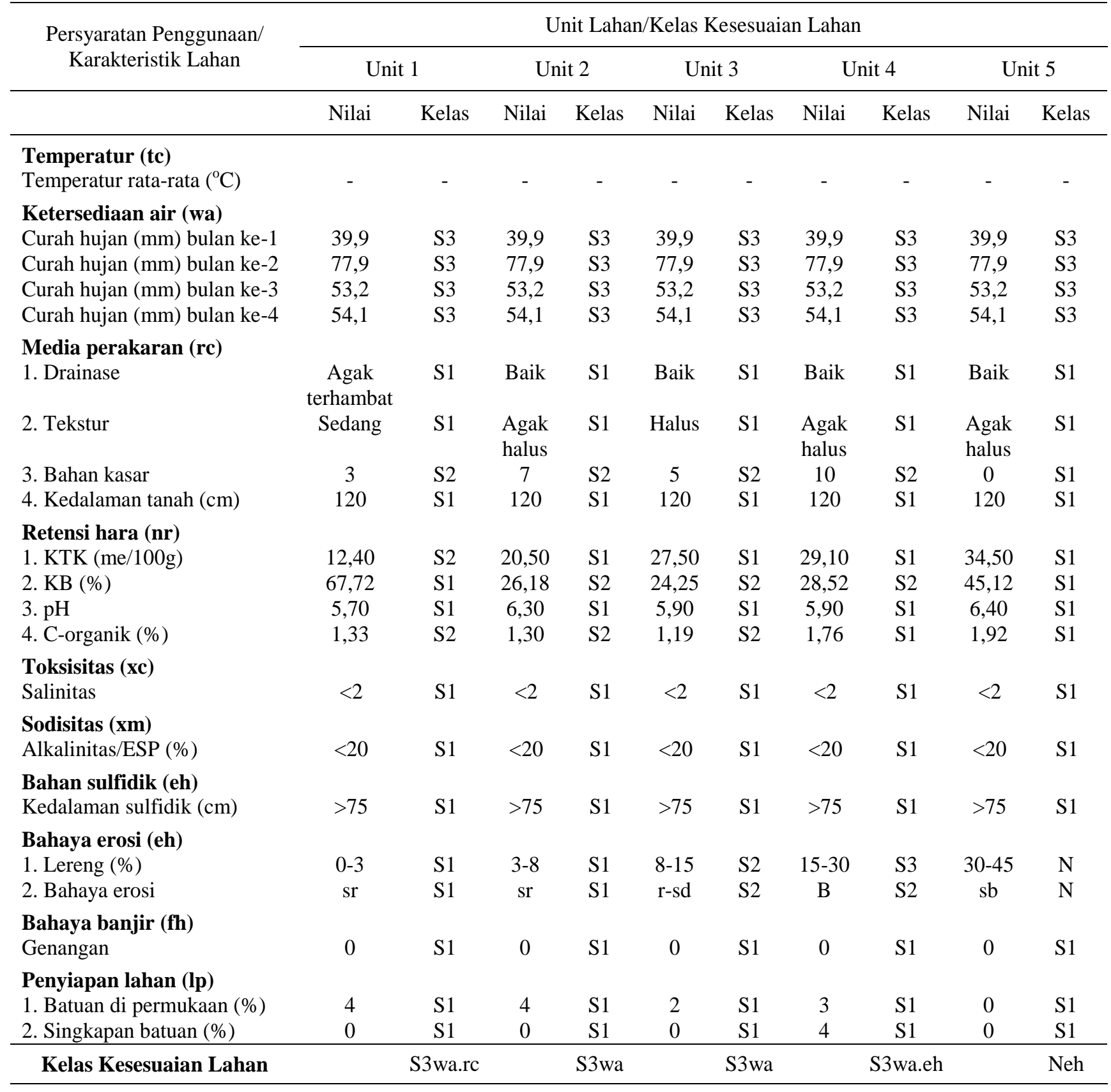

Keterangan: tekstur $: \mathrm{h}=$ halus; $\mathrm{ah}=$ agak halus; $\mathrm{s}=$ sedang; $\mathrm{ak}=$ agak kasar; $\mathrm{k}=\mathrm{kasar}$; bahaya erosi $: \mathrm{sr}=$ sangat ringan; $\mathrm{r}=$ ringan; $\mathrm{sd}=$ sedang; $\mathrm{b}=$ berat; $\mathrm{sb}=$ sangat berat; genangan $: \mathrm{F} 0=$ tanpa genangan, $\mathrm{F} 1=$ ringan $; \mathrm{F} 2=$ sedang; $>\mathrm{F} 3=$ agak berat - berat. Kelas kesesuaian $: \mathrm{S} 1=$ sangat sesuai; $\mathrm{S} 2=$ cukup sesuai; $\mathrm{S} 3$ = sesuai marginal; $\mathrm{N}=$ tidak sesuai

air (wa) (S3wa), sedangkan pada unit lahan 4 memiliki faktor pembatas ketersediaan air dan lereng sehingga termasuk dalam kelas kesesuaian lahan sesuai marginal (S3wa.eh). Untuk faktor pembatas ketersediaan air pada unit lahan 1, 2, 3, dan 4, penanganan yang dapat dilakukan adalah dengan membuat saluran irigasi yang berasal dari sumur bor/pompa dan penanaman dilakukan pada saat masa transisi musim panas ke musim hujan yaitu pada bulan Januari sampai Mei berdasarkan data curah hujan tahun 2015. Pada bulan tersebut, kebutuhan air pada tanaman padi gogo akan tercukupi, yaitu pada bulan pertama tanam dan bulan keempat tanaman padi 
gogo membutuhkan ketersediaan air sebanyak 50 - 100 $\mathrm{mm}$, sedangkan pada bulan kedua dan ketiga mebutuhkan ketersediaan air sebesar 100 - $400 \mathrm{~mm}$. Untuk meningkatkan produksi pertanian pada lahan kering, jalan terbaik yang dapat ditempuh adalah melakukan irigasi ketika tanaman membutuhkan yaitu pada saat tanaman mengalami cekaman air. Saat ini, irigasi pada lahan kering menjadi suatu keharusan agar pertanian tetap menghasilkan sepanjang tahun (Sutono dkk., 2007).

Berdasarkan hasil pengamatan langsung di lapang, pada Unit lahan 4 tingkat kemiringan lereng sebesar 15 - 30\% yang masuk dalam kelas kesesuaian lahan sesuai marginal (S3) dan pada Unit lahan 5 tingkat kemiringan lereng sebesar 30 - 45\% yang masuk kedalam kelas kesesuaian lahan tidak sesuai (N). Menurut Banuwa dan Zulkarnain (2013), untuk memperbaiki kemiringan lereng sebesar $15-30 \%$ dapat dilakukan penanaman dengan cara mengikuti arah kontur lahan, sedangkan pada unit lahan 5 dengan kemiringan lereng sebesar 30 $-45 \%$ dapat dilakukan pembuatan teras tangga/bangku (Hardjowigeno, 2007).

Pada unit lahan 5 hasil produksinya lebih tinggi dari pada unit lahan yang lain. Hal ini dikarenakan pada unit lahan 5 belum pernah dilakukan budidaya tanaman apapun sebelumnya, sehingga ketersediaan hara masih banyak dan kandungan C-organik tinggi yang menandakan lahan tersebut subur. Penurunan hasil produksi juga dipengaruhi oleh hama pengganggu berupa walang sangit yang menyerang butir padi yang baru tumbuh dengan cara menghisap butir padi sampai kering yang mengakibatkan gabah padi menjadi hampa. Penurunan produksi dapat dilihat dari persentase gabah hampa di setiap unit lahan. Pada unit lahan 1 persentase gabah hampa sebesar $58,4 \%$, pada unit lahan 2 persentase gabah hampa sebesar $56 \%$, pada unit lahan 3 sebesar $51,4 \%$, pada unit lahan 4 sebesar $49,6 \%$, pada unit lahan 5 sebesar 32,8\%.

Pada umumnya, faktor pembatas berupa hama walang sangit menyebar luas di semua lokasi penelitian dan berpengaruh terhadap produksi padi gogo walaupun pengendalian sudah termasuk intensif ( 3 hari sekali) dengan menggunakan insektisida racun kontak berupa Baycarb 500 EC. Namun, faktor pembatas lain juga berpengaruh terhadap produksi padi gogo pada setiap unit lahan.

Kesesuaian Lahan Kuantitatif. Untuk mengetahui tingkat kelayakan usahatani padi gogo di lahan penelitian, digunakan analisis $R / C$ Ratio, dimana nilai $R /$ $C$ Ratio adalah perbandingan atau nisbah antara penerimaan dan biaya. Bila nilai $\mathrm{R} / \mathrm{C}=1$ artinya usaha dalam keadaan tidak untung dan tidak rugi, bila R/C >1, maka usaha dalam keadaan yang menguntungkan, tetapi apabila nilai $\mathrm{R} / \mathrm{C}<1$ maka usaha mengalami kerugian (Soekartawi, 1995).

Pada Unit lahan 1, penerimaan yang didapat sebesar Rp 5.555.000,00 dan pengeluaran sebesar Rp 12.865.000,00 sehingga didapat nilai $\mathrm{R} / \mathrm{C} 0,431$ dengan nilai $\mathrm{R} / \mathrm{C}<1$, yang artinya usaha tani padi gogo pada Unit lahan 1 mengalami kerugian. Penerimaan pada Unit lahan 2 sebesar Rp 12.925.000,00 dan pengeluaran sebesar $\mathrm{Rp}$ 12.865.000,00 sehingga didapat nilai R/C sebesar 1,004 , berarti $\mathrm{R} / \mathrm{C}>1$ artinya usahatani padi gogo pada Unit lahan 2 mengalami keuntungan.

Penerimaan pada Unit lahan 3 sebesar Rp 14.865.000,00 dan pengeluaran sebesar $\mathrm{Rp}$ 12.865.000,00 sehingga didapat nilai $\mathrm{R} / \mathrm{C} 1,141$, dengan nilai $\mathrm{R} / \mathrm{C}>1$ artinya usahatani padi gogo pada Unit lahan 3 mengalami keuntungan. Penerimaan pada Unit lahan 4, yaitu sebesar $\mathrm{Rp} 15.235 .000,00$ dan pengeluaran sebesar Rp 12.865.000,00 dengan nilai $\mathrm{R} / \mathrm{C}$ sebesar 1,184 berarti $\mathrm{R} / \mathrm{C}>1$ artinya usahatani padi gogo pada Unit lahan 4 mengalami keuntungan. Penerimaan pada Unit lahan 5 sebesar Rp 19.085.000,00 dan pengeluaran sebesar $\mathrm{Rp}$ 12.865.000,00 dengan nilai $\mathrm{R} / \mathrm{C}$ sebesar 1,483 berarti $\mathrm{R} / \mathrm{C}>1$, artinya usahatani padi gogo pada Unit lahan 5 mengalami keuntungan.

\section{KESIMPULAN}

Berdasarkan hasil penelitian maka dapat diambil kesimpulan yaitu kelas kesesuaian lahan untuk tanaman padi gogo (Oryza sativa L.) di Laboratorium Lapang Terpadu Fakultas Pertanian Universitas Lampung adalah berdasarkan kemiringan lereng. Pada unit lahan 1, 2, dan 3 termasuk dalam kelas kesesuaian lahan sesuai marginal dengan faktor pembatas ketersediaan air (S3wa), pada unit lahan 4 termasuk kelas kesesuaian lahan sesuai marginal dengan faktor pembatas ketersediaan air, lereng dan bahaya erosi (S3wa.eh), dan pada unit lahan 5 termasuk dalam kelas kesesuaian lahan tidak sesuai dengan faktor pembatas lereng dan bahaya erosi (Neh).

Secara finansial, usaha tani tanaman padi gogo di Laboratorium Lapang Terpadu Fakultas Pertanian Universitas Lampung adalah menguntungkan dan layak untuk dilanjutkan pada unit lahan 2, 3, 4, dan 5. Hal ini dibuktikan dari hasil perhitungan yang menunjukan bahwa nilai R/C pada unit lahan 2 sebesar 1,004, pada unit lahan 3 sebesar 1,141, pada unit lahan 4 sebesar 1,184, dan pada unit lahan 5 sebesar 1,483. 


\section{DAFTAR PUSTAKA}

Banuwa, I. S, dan I. Zulkarnain. 2013. Evaluasi kemampuan lahan laboratorium lapang terpadu. Laporan Penelitian. Fakultas Pertanian Universitas Lampung. Bandar Lampung.

Djaenuddin, D., H. Marwan., H. Subagyo, A. Mulyani, dan N. Suharta. 2003. Kriteria Kesesuaian Lahan untuk Komoditas Pertanian. Departemen Pertanian. 264 hlm.

Mas'ud, P. 1992. Telaah Kesuburan Tanah. Angkasa. Bandung.
Prasetyo, Y. T. 2007. Bertanam Padi Gogo Tanpa Olah Tanah. Penebar Swadaya. Jakarta.

Pujiharti, Y., J. Barus., dan B. Wijayanto. 2008. Teknologi Budidaya Padi. Balai Besar Pengkajian dan Pengembangan Teknologi Pertanian, Badan Penelitian dan Pengembangan Pertanian. Bogor.

Soekartawi. 1995. Analisis Usaha Tani. Universitas Indonesia. Jakarta.

Sutono. S., W. Hartatik, dan J. Purnomo. 2007. Penerapan Teknologi Pengelolaan Air dan Hara Terpadu untuk Bawang Merah di Donggala. Badan Penelitian Tanah. Bogor. 